OPEN ACCESS

Edited by:

Alpo Juhani Vuorio,

University of Helsinki, Finland

Reviewed by:

Jacques Genest

McGill University, Canada

Martin Proven Bogsrud,

Oslo University Hospital, Norway

Krzysztof Dyrbuś,

Silesian Center for Heart Diseases,

Poland

*Correspondence:

Urh Groselj

urh.groselj@kclj.si

Specialty section:

This article was submitted to

Genetics of Common and Rare

Diseases,

a section of the journal

Frontiers in Genetics

Received: 12 June 2020

Accepted: 20 August 2020

Published: 11 September 2020

Citation:

Marusic T, Sustar U, Sadiq F Kotori V, Mlinaric M, Kovac J, Shafi S,

Khan I, Cevc M,

Trebusak Podkrajsek K, Battelino T

and Groselj U (2020) Genetic

and Clinical Characteristics

of Patients With Homozygous

and Compound Heterozygous

Familial Hypercholesterolemia From

Three Different Populations: Case

Series. Front. Genet. 11:572176.

doi: $10.3389 /$ fgene.2020.572176

\section{Genetic and Clinical Characteristics of Patients With Homozygous and Compound Heterozygous Familial Hypercholesterolemia From Three Different Populations: Case Series}

\author{
Tatiana Marusic ${ }^{1}$, Ursa Sustar ${ }^{1}$, Fouzia Sadiq ${ }^{2}$, Vjosa Kotori ${ }^{3}$, Matej Mlinaric ${ }^{1}$, \\ Jernej Kovac ${ }^{1}$, Saeed Shafi ${ }^{4}$, Iqbal Khan ${ }^{2,5}$, Matija Cevc ${ }^{6}$, \\ Katarina Trebusak Podkrajsek ${ }^{1,7}$, Tadej Battelino ${ }^{1,7}$ and Urh Groselj 1,7* \\ ${ }^{1}$ University Children's Hospital, University Medical Center, Ljubljana, Slovenia, ${ }^{2}$ Shifa Tameer-e-Millat University, Islamabad, \\ Pakistan, ${ }^{3}$ Department of Endocrinology, Pediatric Clinic, University Clinical Center of Kosovo, Pristina, Kosovo, \\ ${ }^{4}$ Department of Anatomy, Shifa Tameer-e-Millat University, Islamabad, Pakistan, ${ }^{5}$ Department of Vascular Surgery, Shifa \\ International Hospital, Islamabad, Pakistan, ${ }^{6}$ Division of Medicine, Centre for Preventive Cardiology, University Medical \\ Centre Ljubljana, Ljubljana, Slovenia, ${ }^{7}$ Faculty of Medicine, University of Ljubljana, Ljubljana, Slovenia
}

Homozygous familial hypercholesterolemia $(\mathrm{HoFH})$ and compound heterozygous familial hypercholesterolemia $(\mathrm{cHeFH})$ are rare disorders generated by disease-causing variants in both alleles of the $L D L R$ or other familial hypercholesterolemia $(\mathrm{FH})$-related genes. $\mathrm{HoFH}$ and $\mathrm{cHeFH}$ are characterized by severely elevated low-density lipoproteincholesterol (LDL-C), frequently leading to early cardiovascular disease. We investigated the genetic and clinical characteristics of $\mathrm{HoFH}$ and $\mathrm{cHeFH}$ patients from the Slovenian $\mathrm{FH}$ registry and/or those who were previously diagnosed or managed at our institution (Slovenian, Pakhtun and Albanian ethnicity), where genetic testing is not available. Our study includes seven patients. Their median age at the time of clinical diagnosis was 6.3 years (2.9-12.9 years); 2/7 were females. Two patients were diagnosed through the universal $\mathrm{FH}$ screening and five patients were diagnosed due to the presence of xanthomas. All the mutations are present in LDLR gene: 7 different genotypes for $\mathrm{HoFH}$ (p.Cys167Leu, p.Asp178Asn, p.Cys243Tyr, p.Gly549Asp, p.Cys27Trp, p.lle585Thr and p.Val797Met) and p.Gly549Asp/p.Gln384Pro genotype for cHeFH patient. The median initial level of LDL-C was $17.0 \mathrm{mmol} / \mathrm{L}$ [655 mg/dL] (range 7.6-21.6 mmol/L). The $\mathrm{HoFH} / \mathrm{cHeFH}$ patients are clinically and genetically very diverse. The clinical criteria (as Simon Broome criteria) might be applicable already in children to raise suspicion of $\mathrm{FH}$ but in some cases fail to distinguish heterozygous $\mathrm{FH}$ and $\mathrm{HoFH} / \mathrm{cHeFH}$ patients. However, genetic testing is helpful in confirming the diagnosis, also for a prompt awareness, better compliance to treatment and family screening.

Keywords: familial hypercholesterolaemia, FH, homozygous, compound heterozygous, LDLR gene 


\section{INTRODUCTION}

Familial Hypercholesterolemia (FH) is an autosomal dominant genetic disorder, characterized by elevated total cholesterol (TC) and LDL-cholesterol (LDL-C) levels, usually accompanied by clinical characteristics and an early onset of cardiovascular disease (CVD), with a variable severity depending on the causative mutation (Moorjani et al., 1993). The prevalence of homozygous $\mathrm{FH}$ is unknown because of underdiagnosis and of a wide spectrum of phenotypes overlapping with heterozygous $\mathrm{FH}(\mathrm{HeFH})$, but is estimated in 1:200,000-300,000 (Sjouke et al., 2015; EAS Familial Hypercholesterolaemia Studies Collaboration et al., 2018; Representatives of the Global Familial Hypercholesterolemia Community et al., 2020).

Homozygous FH can be classified as: a- Real homozygous (HoFH): when the same mutation affects both alleles of one of the major FH-related genes ( $L D L R, A P O B$, or PCSK9); b- Compound heterozygous ( $\mathrm{cHeFH})$ : when different mutations located on different alleles affect one of the major $\mathrm{FH}$-associated genes; cCombined heterozygous: when different mutations affect two different FH-related genes (Masana et al., 2019).

Homozygous FH patients can develop xanthomas and progressive atherosclerosis already in early childhood. If untreated, they develop vascular lesions and CVD before the second decade of life and die before the end of the third decade (Watts et al., 2014; Vallejo-Vaz et al., 2015).

Slovenia has successfully implemented nationwide universal screening for $\mathrm{FH}$ in pre-school children, detecting also the $\mathrm{HoFH} / \mathrm{cHeFH}$ patients (Klancar et al., 2015; Groselj et al., 2018). The implementation and optimization of the routine $\mathrm{FH}$ genetic testing enables us to offer it to other national and foreign centers.

We aimed to analyze characteristics of all patients with $\mathrm{HoFH}$ and $\mathrm{cHeFH}$ genetically diagnosed and/or managed at our center.

\section{MATERIALS AND METHODS}

In 2011, routine $\mathrm{FH}$ genetic diagnosis was introduced at the UMC - University Children's Hospital Ljubljana, which serves as the national accredited genetic testing facility for dyslipidemias (Klancar et al., 2015; Groselj et al., 2018).

The universal hypercholesterolemia screening in children is an obligatory part of the blood check-up at the programed visit in 5-year old children at the primary care pediatricians; if TC is elevated (over $6 \mathrm{mmol} / \mathrm{L}$ or, in case of positive family history, over $5 \mathrm{mmol} / \mathrm{L}$ ), the child is referred to the tertiary center for the $\mathrm{FH}$ genetic screening (Groselj et al., 2018).

We also provide $\mathrm{FH}$ genetic testing to other national and international institutions. Recently, we have been receiving samples from Pakistan and Kosovo (where the major ethnic group is Albanian). The first is a multiracial nation with a very heterogeneous population and without geographical clustering, generally found in other populations (Ajmal et al., 2010; Ahmed et al., 2013). A few common/known mutations are identified but the rest are mainly new mutations (Khan et al., 2014). On the other hand, a study in 2009 of FH in the Albanian population showed a single common mutation in almost half of the probands, but no other recent studies have been published (Diakou et al., 2010). Both populations require efficient genetic testing methods and a laboratory strategy.

The principles of the Declaration of Helsinki were followed and the Slovenian National Medical Ethics Committee (NMEC) approved the study (\#25/12/10, \#63/07/13 and 0120-273/2019/9). The data was also obtained from the National registry of FH and rare dyslipidemias (NMEC \#0120-14/2017/5). Informed consent was obtained from adult patients and parents or legal guardians of minors.

The underlying data is partly available in the Mendeley repository at https://data.mendeley.com/datasets/thpt9htws6/1. The prevalence of $\mathrm{HoFH} / \mathrm{cHeFH}$ in the Slovenian cohort was calculated as the number of live-born children since the implementation of the universal FH screening program in 1995, divided by the number of the $\mathrm{HoFH} / \mathrm{cHeFH}$ patients.

\section{Genetic Analysis}

By the beginning of 2020, around 1150 genetic analyses were performed on pediatric patients with hypercholesterolemia in our genetic laboratory. Genomic DNA was isolated from the patients whole blood samples using the FlexiGene isolation kit (Qiagen, Germany). Three different sequencing methods for FH gene detection were used over time: (1) targeted Sanger sequencing $(n=192)$-LDLR gene and part of exon 26 of APOB gene-, (2) ADH MASTR v2 ready to use next-generation sequencing (NGS) based molecular assay (Multiplicom, Belgium) $(n=190)$-for detection of the variants in coding regions of LDLR, PCSK9, APOE, part of exon 26 (c.10200 to c.11100) of I (Single Nucleotide Variants \& Copy Number Variants), as well as 12 LDL-C raising SNPs for a comprehensive analysis-, and (3) xGen ${ }^{\circledR}$ Lockdown $^{\circledR}$ NGS Probes (IDT, United States) $(n=652)$-for an extended dyslipidemia panel (APOB, LDLR, PCSK9, LDLRAP1) and expanded dyslipidemia panel (ABCA1, ABCG5, ABCG8, ALMS1, APOA1, APOA5, APOC2, APOC3, APOE, CREB3L3, GPIHBP1, LDLRAP1, LIPA, $L M F 1, L P L)$-. Samples were sequenced on MiSeq sequencer with MiSeq Reagent Kit (Illumina, United States) following the manufacturer's protocol including recommendations for quality control parameters. In all samples sequenced with NGS, more than 100 -fold horizontal coverage of the regions of interest (ROI) was achieved. A disease-specific database was used for determining the residual activity information of the known variants (Benito-Vicente et al., 2018). All variants found by the NGS were confirmed by targeted Sanger DNA sequencing.

\section{CASE SERIES}

Patient 1 is a 13 years old boy of Pakhtun origin from Khyber Pakhtunkhwa Province of Pakistan. Two siblings of the patient had died prematurely at ages of 10 and 11 years; only after that the parents sought clinical help. He was clinically diagnosed with $\mathrm{FH}$ at the age of 11 because of xanthomas, corneal arcus and a TC level of $22.9 \mathrm{mmol} / \mathrm{L}$ [ $885 \mathrm{mg} / \mathrm{dL}$ ]. The genetic testing showed three different mutations -p.Cys167Leu, p.Asp178Asn 
and p.Cys243Tyr- in both alleles (HoFH). All family members, except one sister, presented the same mutations in one allele $(\mathrm{HeFH})$. To date, no functional data have been reported about the LDLR activity for these three variants. The patient presented a normal CT coronary angiography and coronary angiogram. He has been treated with atorvastatin $40 \mathrm{mg}$ and ezetimibe $10 \mathrm{mg}$; other therapeutic options are not available in Pakistan.

Patient 2 is a 14 years old male from Kosovo. Before the age of 3 years, his physician observed xanthomas on elbows and knees, suspecting FH. The lipid profile showed cholesterol levels more than $20 \mathrm{mmol} / \mathrm{L}$ (No more biochemical data is available from that country). The family history revealed hypercholesterolemia in both parents, brother and grandmother. He was initially treated in Kosovo with atorvastatin and underwent occasional LDL-apheresis, without any improvement. At 11 years of age, he was referred to Slovenia, confirming a homozygous mutation in the $L D L R$, with less than $2 \%$ of receptor activity. In the clinical center, the initial TC level was $15.8 \mathrm{mmol} / \mathrm{L}$ [610 $\mathrm{mg} / \mathrm{dL}$ ] and LDL-C level was $13.7 \mathrm{mmol} / \mathrm{L}$ $[529 \mathrm{mg} / \mathrm{dL}]$. At that moment he received atorvastatin $40 \mathrm{mg}$ and ezetimibe $10 \mathrm{mg}$. The last carotid Ultrasound (US) at the age of 11 years revealed diffuse non-obstructive atherosclerosis in bilateral carotid arteries; the most significant plaque-type I-II in the right common carotid artery contributing to $30 \%$ stenosis. After that, he has continued with atorvastatin $80 \mathrm{mg}$, ezetimibe $10 \mathrm{mg}$ and PCSK9 inhibitors within a clinical trial, but was a nonresponder to the later. Other therapeutic options are currently not available in Kosovo.

Patient 3, a 6 years old Slovenian girl (of Albanian origin), was recently diagnosed at the universal $\mathrm{FH}$ screening, with an initial TC level of $7.6 \mathrm{mmol} / \mathrm{L}$ [293 $\mathrm{mg} / \mathrm{dL}]$. She was referred to our tertiary care center, where the biochemical test was repeated and later the genetic test revealed an $L D L R$ homozygous mutation with $15-30 \%$ of LDLR activity. She stays asymptomatic and no family history of CVD was found. Until now she had not been introduced to pharmacotherapy.

Patient 4 is a 18 years old Slovenian male (of Albanian origin), diagnosed during the universal $\mathrm{FH}$ screening with TC level of $9.0 \mathrm{mmol} / \mathrm{L}[348 \mathrm{mg} / \mathrm{dL}]$. His parents and brother have hypercholesterolemia. The genetic testing confirmed a homozygous LDLR mutation with $15-30 \%$ of LDLR residual activity. The last carotid US at the age of 16 years had shown a borderline intima-media thickness (cITM) of $0.56 \mathrm{~mm}$. He started with monotherapy of atorvastatin and later required dual therapy with higher doses of atorvastatin and ezetimibe. At the age of 16 he was enrolled in the clinical trial with PCSK9 inhibitors. His latest TC and LDL-C levels were $6 \mathrm{mmol} / \mathrm{L}$ [232 $\mathrm{mg} / \mathrm{dL}]$ and $4.5 \mathrm{mmol} / \mathrm{L}$ [174 $\mathrm{mg} / \mathrm{dL}]$, respectively.

Patient 5 is a 31 years old Slovenian male with FH diagnosed in april 1993, at the age of 4, due to the presence of xanthomas. Both parents and sister have HeFH. His initial TC level was $24.8 \mathrm{mmol} / \mathrm{L}[959 \mathrm{mg} / \mathrm{dL}]$. The genetic testing confirmed a homozygous mutation in $L D L R$. To date, no functional data were found about LDLR residual activity for this mutation. The last carotid US studies at the age of 30 years have shown a thickened intima-media (cITM $0.903 \mathrm{~mm}$ ). He was treated with atorvastatin, LDL-apheresis and simvastatin to no effect. Finally, he required liver transplantation at the age of 16 , with remarkable decrease of TC and LDL levels.

Patient 6 is a 43 years old Slovene female clinically diagnosed with hypercholesterolemia at the age of 12 because of a strong family history and an elevated TC (more than $19 \mathrm{mmol} / \mathrm{L}$ ). Her father died at 53 years old because of myocardial infarction and her mother also presented with coronary heart disease after the age of 60 . She had a bad compliance to the combined therapy to atorvastatin $40 \mathrm{mg}$ and ezetimibe $10 \mathrm{mg}$. She was receiving LDL-apheresis for several years (data about frequency of treatment unavailable), discontinued it later because of the adverse effects (strong headache, dizziness, weight gain, cough). When she was 38 years old she suffered an acute coronary syndrome, whereas coronary angiography revealed stenosis of the left main coronary artery and distal right coronary artery. She was diagnosed with homozygous mutation in $L D L R$, with an unknown residual activity. She transiently received PCSK9 inhibitor and lomitapide, but had discontinued the treatments due to side effects.

Patient 7 is a 7 years old male from Kosovo. He was diagnosed with $\mathrm{FH}$ at the age of 6 after an abdominal pain event. At the examination, the physician discovered small xanthomas in the sacral region and the biochemical testing showed CT levels of $20.4 \mathrm{mmol} / \mathrm{L}$ [789 mg/dL]. His mother also presented hypercholesterolemia. The genetic analysis confirmed cHeFH; a variant in p.Gly549Asp, with less than $2 \%$ of LDLR residual activity, and another in p.Gln384Pro, with unknown residual activity. He has a normal carotid US. His current therapy consists of atorvastatin $80 \mathrm{mg}$ and ezetimibe $10 \mathrm{mg}$ and he is showing good response to the therapy. Other therapeutic options are not available in Kosovo.

Clinical and genetic features are summarized in Table $\mathbf{1}$ and Figure 1. Biochemical values and therapy are plotted in Figures 2A,B.

\section{RESULTS}

\section{Demographics}

All patients had a family history of early CVD and/or hypercholesterolemia, except patient 3 . At the time of the clinical diagnosis, the patient's median age was 6.3 (2.9-12.9) years. Five patients were symptomatic at the diagnosis (presence of xanthomas and/or corneal arcus), while two were asymptomatic detected through the FH screening program. Four patients were born in Slovenia: both patients born after the implementation of the universal FH screening in this country, were detected through the program; the older two HoFH patients were born prior to the program implementation. The pre-treatment median TC level was $17.2 \mathrm{mmol} / \mathrm{L}[665 \mathrm{mg} / \mathrm{dL}](7.6-24.8 \mathrm{mmol} / \mathrm{L})$ and median LDL-C level was $17.0 \mathrm{mmol} / \mathrm{L}[655 \mathrm{mg} / \mathrm{dL}](7.6-21.6 \mathrm{mmol} / \mathrm{L})$.

In the carotid US, an increased carotid artery intimamedia thickness (cIMT) or atherosclerosis signs were found in cases 2, 4 and 5. One patient (case 6) with angina pectoris underwent coronarography, detecting stenosis of left and right coronary artery. 
TABLE 1 | Phenotypic and genotypic features of our cohort of $\mathrm{HoFH}$ and $\mathrm{CHeFH}$ patients.

\begin{tabular}{|c|c|c|c|c|c|c|c|c|}
\hline \multicolumn{2}{|l|}{ Patient } & 1 & 2 & 3 & 4 & 5 & 6 & 7 \\
\hline \multicolumn{2}{|l|}{ Age (years) } & 13.0 & 14.0 & 6.9 & 18.5 & 31.6 & 43.0 & 7.9 \\
\hline \multicolumn{2}{|l|}{ Gender } & M & M & $\mathrm{F}$ & M & M & $\mathrm{F}$ & M \\
\hline \multicolumn{2}{|l|}{ Ethnicity } & Pakhtun & Albanian & Albanian & Albanian & Slovene & Slovene & Albanian \\
\hline \multirow[t]{6}{*}{ Genetic desorder } & Zygosity & homozygous & homozygous & homozygous & homozygous & homozygous & homozygous & $\begin{array}{l}\text { compound } \\
\text { heterozygous }\end{array}$ \\
\hline & FH-related gen & $L D L R$ & $L D L R$ & $L D L R$ & $L D L R$ & $L D L R$ & $L D L R$ & $L D L R$ \\
\hline & Genome mutation & $\begin{array}{l}\text { c.[500_501delinsTA; } \\
532 G>A ; \\
728 G>A] \\
\text { c. [500_501delinsTA; } \\
532 G>A ; \\
728 G>A]\end{array}$ & $\begin{array}{l}\text { c. }[1646 G>A] \\
\text { c. }[1646 G>A]\end{array}$ & $\begin{array}{l}\text { c. }[81 C>G] ; \\
\text { c. }[81 C>G]\end{array}$ & $\begin{array}{l}\text { c. }[81 C>G] ; \\
\text { c. }[81 C>G]\end{array}$ & $\begin{array}{l}\text { c. }[1773 T>C] ; \\
\text { c. }[1773 T>C]\end{array}$ & $\begin{array}{l}\text { c. }[2389 G>A] \\
\text { c. }[2389 G>A]\end{array}$ & $\begin{array}{l}\text { c. }[1151 A>C] \\
\text { c. }[1646 G>A]\end{array}$ \\
\hline & Exon & $4,4,5$ & 11 & 2 & 2 & 12 & 17 & 8,11 \\
\hline & Protein mutation & $\begin{array}{l}\text { Cys167Leu; } \\
\text { Asp178Asn; } \\
\text { Cys243Tyr }\end{array}$ & p.Gly549Asp & p.Cys27Trp & p.Cys27Trp & P.lle585Thr & p. Val797Met & $\begin{array}{l}\text { p. Gly549Asp; } \\
\text { p.Gln384Pro }\end{array}$ \\
\hline & $\begin{array}{l}\text { Residual LDLR } \\
\text { activity }\end{array}$ & not determined & $<2 \%$ & $15-30 \%$ & $15-30 \%$ & not determined & not determined & $\begin{array}{l}\text { p.Gly549Asp }<2 \% \\
\text { p.Gln384Pro: not } \\
\text { determined }\end{array}$ \\
\hline \multicolumn{2}{|l|}{ Screening type } & Other & Other & Universal & Universal & Other & Other & Other \\
\hline \multicolumn{2}{|c|}{ Age of diagnosis (years) } & 11.1 & 2.9 & 6.3 & 5.5 & 4.3 & 12.9 & 7.3 \\
\hline \multicolumn{2}{|l|}{ Symtoms } & Xanthomas & Xanthomas & Asymtomatic & Asymtomatic & Xanthomas & $\begin{array}{l}\text { Angina pectoris, } \\
\text { xanthomas }\end{array}$ & Xanthomas \\
\hline \multicolumn{2}{|l|}{ Corneal arcus } & Yes & No & No & No & No & No & no \\
\hline \multicolumn{2}{|c|}{ Cardiovascular exams } & $\begin{array}{l}\text { CT coronary } \\
\text { angiography and } \\
\text { coronary } \\
\text { angiogram: normal }\end{array}$ & $\begin{array}{l}\text { Carotid US: diffuse } \\
\text { non- obstructive } \\
\text { atherosclerosis in } \\
\text { both carotid } \\
\text { arteries. In right } \\
\text { CCA: plaque type } \\
\text { I-II (30\% stenosis) }\end{array}$ & No data & $\begin{array}{l}\text { Carotid US: } \\
\text { cIMT = 0,556 mm }\end{array}$ & $\begin{array}{l}\text { Carotid US: } \\
\text { CIMT = 0,903 mm }\end{array}$ & $\begin{array}{l}\text { Coronarography: } \\
\text { stenosis of left } \\
\text { coronary artery, } \\
\text { lower stenosis of } \\
\text { right coronary } \\
\text { artery }\end{array}$ & Carotid US: Normal \\
\hline \multirow[t]{3}{*}{$\mathrm{TC}(\mathrm{mmol} / \mathrm{l})$} & First & 22.9 & 15.8 & 7.6 & 9.0 & 24.8 & 17.2 & 20.4 \\
\hline & Last & 17.5 & 18.2 & 7.0 & 6.0 & 7.6 & 16.2 & 11 \\
\hline & $\downarrow$ & $23.4 \%$ & $-15.2 \%$ & $7.9 \%$ & $33.3 \%$ & $69.4 \%$ & $5.8 \%$ & $46.1 \%$ \\
\hline \multirow[t]{3}{*}{ LDL-C (mmol/l) } & First & 20.5 & 13.7 & No data & 7.6 & 21.6 & 15.4 & 18.5 \\
\hline & Last & 16.0 & 17.2 & 5.5 & 4.5 & 6.3 & 14.4 & 10.1 \\
\hline & $\downarrow$ & $22.0 \%$ & $-25.5 \%$ & - & $40.8 \%$ & $70.8 \%$ & $6.5 \%$ & $45.4 \%$ \\
\hline
\end{tabular}




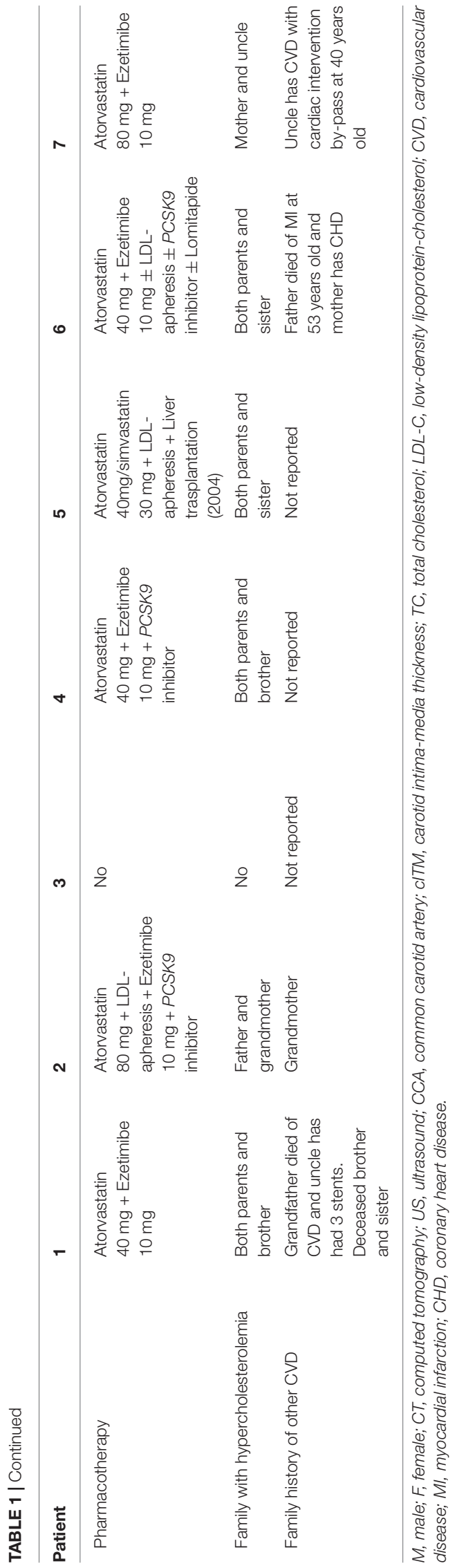

\section{Genotypes}

Genetic evaluation confirmed mutations in $L D L R$ gene in all of the patients (OMIM \#143890). Six patients were confirmed as $\mathrm{HoFH}$ and one as $\mathrm{cHeFH}$. The $\mathrm{HoFH}$ patients present the mutations p.Gly549Asp, p.Cys27Trp, p.Ile585Thr, p.Val797Met, p.Asp178Asn, p.Cys243Tyr, and p.Cys167Leu (the last three variants are present in each allele of patient 1 ). Case 7 presents the variants p.Gly549Asp and p.Gln384Pro in each allele (cHeFH) (Table 1). The cascade children-parent testing was performed for patients number 1,2,4 and 5, confirming all their parents and some of the siblings are carriers of disease-causing variants (Figure 1). The genetic testing for family members of patients 3 , 6 and 7 were unavailable.

\section{Treatment}

As a response to treatment, the median TC and LDL-C decreased by 28 and $31 \%$, respectively. The treatment response is summarized in Figures 2A,B and specified in the Mendeley database $^{1}$. Six patients were treated with statins, five with ezetimibe, three with PCSK9 inhibitors and one with lomitapide. Three patients received LDL-apheresis. One patient had liver transplantation at the age of 16 with excellent response. It is worth noting the distinguished response presented in the $\mathrm{cHeFH}$ patient (46\%), compared to the mean response in $\mathrm{HoFH}$ patients.

\section{DISCUSSION}

Homozygous FH is an ultra-rare disease, but newer data show it to be more frequent as previously assumed. Sjouke et al. (2014) calculated the prevalence of $\mathrm{HoFH}$ and $\mathrm{cHeFH}$ in the Netherlands population ranges from $1 / 371,608$ to $1 / 407,863$. The prevalence in Slovenia was estimated at around $1 / 256,340$, calculated by dividing the number of tested children with the number of confirmed $\mathrm{HoFH} / \mathrm{cHeFH}$ cases in that period.

$\mathrm{Up}$ to date, there is no international unanimity on $\mathrm{FH}$ detection strategies; some guidelines recommend the cascade screening as the most cost-effective strategy (Santos et al., 2016). Others, like the US National Lipid Association (Goldberg et al., 2011) and American Academy of Pediatrics (Expert Panel on Integrated Guidelines for Cardiovascular Health, and Risk Reduction in Children, and Adolescents, 2011) recommend universal screening. Thus, each country adopts a screening method based on local scientific societies or experts (Ibarretxe et al., 2018; Umans-Eckenhausen et al., 2001; Representatives of the Global Familial Hypercholesterolemia Community et al., 2020). For example, in Sjouke's report in the Netherlands, 36 patients (73\%) were diagnosed by referrals from pediatricians because of the presence of symptoms, while 13 patients (27\%) were detected through cascade screening (Sjouke et al., 2014). Slovenia is the only country with implemented nationwide universal FH screening in pre-school children (with routinely implemented genetic FH diagnostics), detecting also the last two of our $\mathrm{HoFH}$ patients (the first

\footnotetext{
${ }^{1}$ http://dx.doi.org/10.17632/thpt9htws6.1
} 

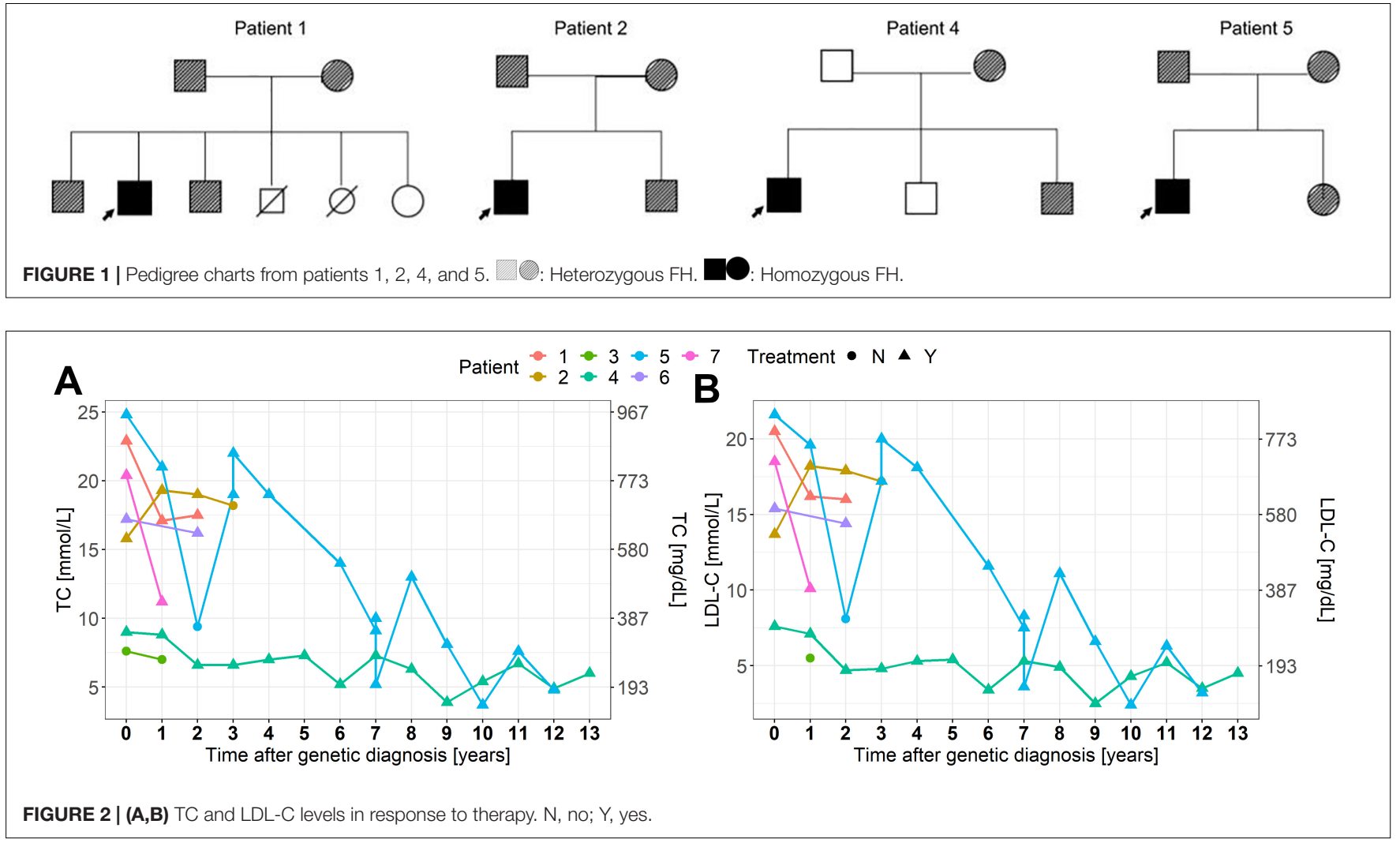

two were diagnosed prior to the program implementation) (Klancar et al., 2015; Groselj et al., 2018). However, beyond the initial screening method, almost all of the literature agrees on the importance of genetic testing. Recognition of a pathogenic $\mathrm{FH}$ mutation guides the cascade screening in the family, as well as the incorporation of genetic testing into cascade screening improves the detection rate for $\mathrm{FH}$ (Knowles et al., 2017). Furthermore, between $\mathrm{HoFH}$ and $\mathrm{cHeFH}$ patients some more subtle differences in the genotype-phenotype correlations or even regarding the response to therapies might exist due to inter-allele interactions and possibility that the phenotype is determined by the allele leading to the higher residual activity (as generally in inborn errors of metabolism) (Groselj et al., 2012).

We reported six patients with $\mathrm{HoFH}$ and one with $\mathrm{cHeFH}$. All of them (100\%) have mutations in $L D L R$, while other European reports show a prevalence of $91 \%$ in Netherlands (Sjouke et al., 2014), 75\% in France (Bruckert et al., 2017), and $71 \%$ in Spain (Alonso et al., 2016). Our cohort's mean age at the time of clinical diagnosis was 7.2 years old, ranging from 2.9 to 12.9 years. In other European studies the mean age at the time of molecular diagnosis were: in Austria and France 6.6 and 7.5 years, respectively, in Belgium 2.45 years, while in Netherlands it was 28.2 years (49 cases included, 068 years old).

All the patients meet the $\mathrm{FH}$ Dutch diagnostic criteria for definite $\mathrm{FH}$, except patient 3 and 4, who had a possible and probable $\mathrm{FH}$, respectively, both detected by universal
FH screening (Klancar et al., 2015; Groselj et al., 2018); all patients were genetically diagnosed for FH. Four patients presented xanthomas, whereas in France (Bruckert et al., 2017), Austria (Widhalm et al., 2017), and Belgium (Sanna et al., 2016) almost all of the patients had skin stigmata at the diagnosis.

The pre-treatment mean LDL-C level of our patients was $16.2 \mathrm{mmol} / \mathrm{L}[627 \mathrm{mg} / \mathrm{dL}$ ] (but with quite wide range 7.6$21.6 \mathrm{mmol} / \mathrm{L})$. Other European reports mostly showed similar initial LDL-C levels: Netherlands $12.9 \mathrm{mmol} / \mathrm{L}$ [498 mg/dL]; Belgium $19.6 \mathrm{mmol} / \mathrm{L}$ [757 mg/dL]; Austria $16.5 \mathrm{mmol} / \mathrm{L}$ [638 $\mathrm{mg} / \mathrm{dL}$ ] and France $13.2 \mathrm{mmol} / \mathrm{L}$ [510 mg/dL] (Sjouke et al., 2014; Sanna et al., 2016; Bruckert et al., 2017; Widhalm et al., 2017).

Regarding CVD, in our cohort four patients showed atherosclerotic signs (plaques in the carotid arteries, increased cITM or coronary stenosis) and one patient (case 6) also presented angina pectoris. In the United Kingdom, Thompson et al. (2015) reported that the most frequent complications in these patients were coronary heart disease and aortic stenosis.

Homozygous $\mathrm{FH}$ is usually very difficult to manage and the medical treatment often combines several cholesterollowering drugs (Cuchel et al., 2014). Initially, statins with ezetimibe are introduced and in responsive patients also PCSK9 inhibitors, but frequently do not result in a satisfactory reductions of either TC or LDL-C levels, especially in moderate and severe $\mathrm{HoFH}$ patients, which have the highest risk of CVD (Kolansky et al., 2008; Rajendran et al., 2013). For 


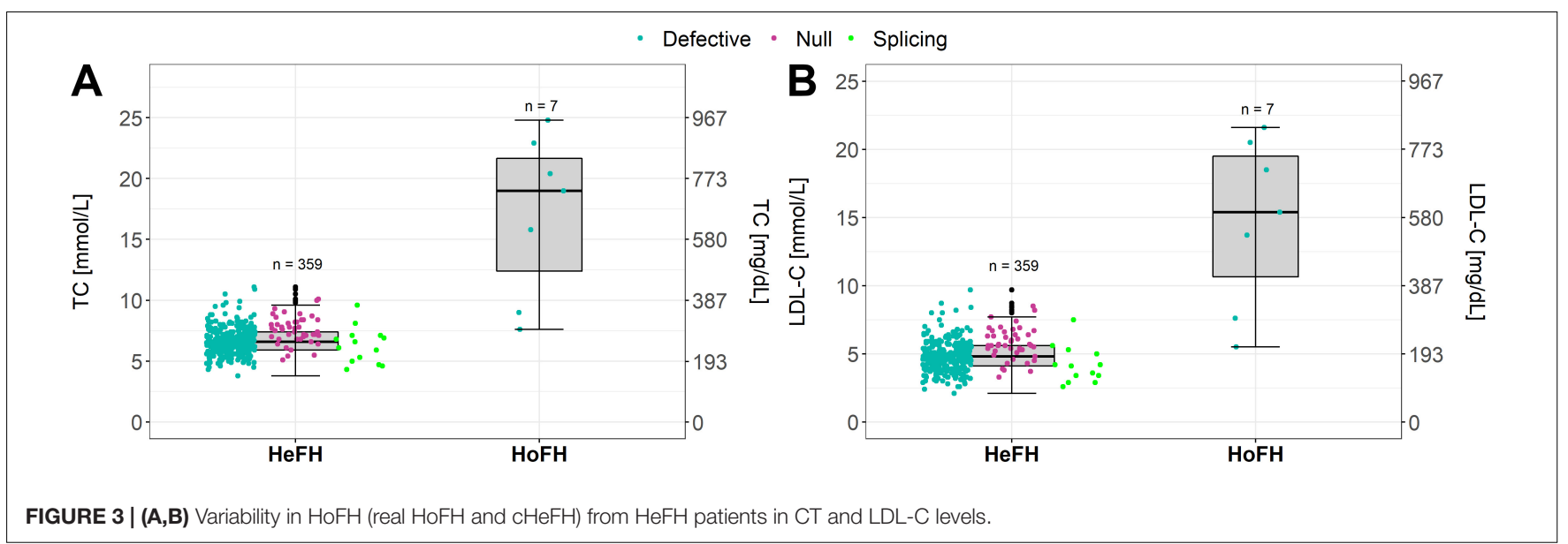

over 30 years, LDL-apheresis has been used, becoming a mainstay in the management of the disease and it is currently considered the most safe and effective treatment (Julius, 2017). If LDL-apheresis is not successful, liver transplantation can be an alternative, considering also as a successful therapy in other metabolic liver diseases (McKiernan, 2017). In the Brussels cohort published by Sanna, the median reduction in TC in response to pharmacological treatment was $47 \%$ (Sanna et al., 2016). In our cohort, we observed a median decrease of TC levels in response to the combined treatment by $28 \%$ (range from a reduction of $69 \%$ to an increase of $15 \%$ besides the therapy). A huge variability in the treatment response is observed among our patients (Figures 2A,B). We could recognize the differences depending on the approach to therapies and on patient adherence, such as cases 2 and 6 . In developing countries, the access to modern diagnostic and therapeutic methods is still limited, resulting in patients failure in reaching treatment goals and also in inadequate management of CVD (Representatives of the Global Familial Hypercholesterolemia Community et al., 2020).

Groselj et al. (2018) reported that around 45\% of participants referred from the Slovenian universal FH screening presented a disease-causing genetic variant for $\mathrm{FH}$, mostly heterozygous. Our institution could compare the TC and LDL-C levels of $\mathrm{HeFH}$ patients with the $\mathrm{HoFH} / \mathrm{cHeFH}$ patients (Figures 3A,B). In concordance with the literature (Santos et al., 2016; Sturm et al., 2018; Berberich and Hegele, 2019), our cohort shows to be clinically and genetically very diverse, overlapping with $\mathrm{HeFH}$ phenotypes. The clinical criteria (as Simon Broome criteria) might be applicable already in children to raise suspicion of $\mathrm{FH}$ but in some cases fail to distinguish $\mathrm{HeFH}$ and $\mathrm{HoFH} / \mathrm{cHeFH}$ patients. As reported previously, consideration of a diagnosis of $\mathrm{HoFH} / \mathrm{cHeFH}$ should not be limited to those with very high LDL-C levels (Raal et al., 2016). Other factors besides Mendelian inheritance also play a role in the $\mathrm{FH}$ : polygenic variants, gene-environment interactions and non-mendelian mechanisms, such as epigenetic (Hooper et al., 2018; Berberich and Hegele, 2019).
Because of the retrospective design, our report has some limitations in data interpretation and not all the data of individual patients or their relatives were available to be included.

\section{CONCLUSION}

$\mathrm{HoFH} / \mathrm{cHeFH}$ patients are clinically heterogeneous, possibly even overlapping with $\mathrm{HeFH}$ patients, highlighting the importance of establishing the genetic diagnosis. In addition, public policies are needed to improve early detection, family screening, adequate therapies, and appropriate follow-up. $\mathrm{HoFH} / \mathrm{cHeFH}$ patients in developing countries frequently lack even basic access to diagnostics, management and adequate therapeutic options, leading to the inequality of outcomes. This should be better addressed at the global level.

\section{PATIENTS PERSPECTIVE}

Nowadays, in Slovenia patients have good access to genetic diagnosis, early detection (universal FH screening) and the current methods of treatment, which is not the case in Kosovo and in Pakistan.

\section{DATA AVAILABILITY STATEMENT}

The datasets presented in this study can be found in online repositories. The names of the repository/repositories and accession number(s) can be found in the manuscript/ supplementary material.

\section{ETHICS STATEMENT}

Written consent was obtained from the participants to conduct clinical examination, conducting clinical and laboratory investigations, including genetic studies and publishing the patient's data in scientific journals. 


\section{AUTHOR CONTRIBUTIONS}

UG and TM conceptualized and designed the study, performed the clinical work, carried out the initial analyses, drafted the initial manuscript, and reviewed and revised the manuscript. US, MM, MC, JK, FS, SS, IK, and VK performed the clinical work, designed the data collection instruments, and reviewed and revised the manuscript. TB and KT coordinated and supervised data collection, and critically reviewed the manuscript for important intellectual content. All authors approved the final manuscript as submitted and agree to be accountable for all aspects of the work.

\section{REFERENCES}

Ahmed, W., Whittall, R., Riaz, M., Ajmal, M., Sadeque, A., Ayub, H., et al. (2013). The genetic spectrum of familial hypercholesterolemia in Pakistan. Clin. Chim. Acta 421, 219-225. doi: 10.1016/j.cca.2013.03.017

Ajmal, M., Ahmed, W., Sadeque, A., Benish Ali, S. H., Bokhari, S. H., Ahmed, N., et al. (2010). Identification of a recurrent insertion mutation in the LDLR gene in a Pakistani family with autosomal dominant hypercholesterolemia. Mol. Biol. Rep. 37, 3869-3875. doi: 10.1007/s11033-010-0043-0

Alonso, R., Diaz-Diaz, J. L., Arrieta, F., Fuentes-Jiménez, F., De Andres, R., Saenz, P., et al. (2016). Clinical and molecular characteristics of homozygous familial hypercholesterolemia patients: insights from SAFEHEART registry. J. Clin. Lipidol. 10, 953-961. doi: 10.1016/j.jacl.2016.04.006

Benito-Vicente, A., Uribe, K. B., Jebari, S., Galicia-Garcia, U., Ostolaza, H., and Martin, C. (2018). Validation of LDLr activity as a tool to improve genetic diagnosis of familial hypercholesterolemia: a retrospective on functional characterization of LDLr variants. Int. J. Mol. Sci 19:1676. doi: 10.3390/ ijms 19061676

Berberich, A. J., and Hegele, R. A. (2019). The complex molecular genetics of familial hypercholesterolaemia. Nat. Rev. Cardiol. 16, 9-20. doi: 10.1038/ s41569-018-0052-6

Bruckert, E., Kalmykova, O., Bittar, R., Carreau, V., Béliard, S., Saheb, S., et al. (2017). Long-term outcome in 53 patients with homozygous familial hypercholesterolaemia in a single centre in France. Atherosclerosis 257, 130-137. doi: 10.1016/j.atherosclerosis.2017.01.015

Cuchel, M., Bruckert, E., Ginsberg, H. N., Raal, F. J., Santos, R. D., Hegele, R. A., et al. (2014). Homozygous familial hypercholesterolaemia: new insights and guidance for clinicians to improve detection and clinical management. A position paper from the consensus panel on Familial Hypercholesterolaemia of the European Atherosclerosis Society. Eur. Heart J. 35, 2146-2157. doi: 10.1093/eurheartj/ehu274

Diakou, M., Miltiadous, G., Xenophontos, S., Cariolou, M., and Heta, N. (2010). Characterization of low density lipoprotein receptor (LDLR) gene mutations in Albania. Arch. Med. Sci. 6, 198-200. doi: 10.5114/aoms.2010.13894

EAS Familial Hypercholesterolaemia Studies Collaboration, Vallejo-Vaz, A. J., De Marco, M., Stevens, C. A., Akram, A., Freiberger, T., et al. (2018). Overview of the current status of familial hypercholesterolaemia care in over 60 countries - The EAS Familial Hypercholesterolaemia Studies Collaboration (FHSC). Atherosclerosis 277, 234-255.

Expert Panel on Integrated Guidelines for Cardiovascular Health, and Risk Reduction in Children, and Adolescents (2011). Expert panel on integrated guidelines for cardiovascular health and risk reduction in children and adolescents. Summary report. Pediatrics 128, 213-256.

Goldberg, A. C., Hopkins, P. N., Toth, P. P., Ballantyne, C. M., Rader, D. J., Robinson, J. G., et al. (2011). Familial hypercholesterolemia: screening, diagnosis and management of pediatric and adult patients: clinical guidance from the national lipid association expert panel on familial hypercholesterolemia. J. Clin. Lipidol. 5, 1-8. doi: 10.1016/j.jacl.2011.04.003

Groselj, U., Kovac, J., Sustar, U., Mlinaric, M., Fras, Z., Trebusak Podkrajsek, K., et al. (2018). Universal screening for familial hypercholesterolemia in children:

\section{FUNDING}

This work was partly supported by the Slovenian National Research Agency, Bleiweisova cesta 30, SI-1000 Ljubljana, Slovenia (grants P3-0343, J3-4116, J3-6800, J3-6800, and J3-6798).

\section{ACKNOWLEDGMENTS}

We would like to thank all patients and their families for participation and nurses for their collaboration with the families.

the Slovenian model and literature review. Atherosclerosis 277, 383-391. doi: 10.1016/j.atherosclerosis.2018.06.858

Groselj, U., Zerjav Tansek, M., Kovac, J., Hovnik, T., Trebusak Podkrajsek, K., and Battelino, T. (2012). Five novel mutations and two large deletions in a population analysis of the phenylalanine hydroxylase gene. Mol. Genet. Metab. 106, 142-148. doi: 10.1016/j.ymgme.2012.03.015

Hooper, A. J., Burnett, J. R., Bell, D. A., and Watts, G. F. (2018). The present and the future of genetic testing in familial. hypercholesterolemia: opportunities and caveats. Curr. Atherosclerosis Rep. 20:31. doi: 10.1007/s11883-018-0731-0

Ibarretxe, D., Rodríguez-Borjabad, C., Feliu, A., Bilbao, J. A., Masana, L., Plana, N., et al. (2018). Detecting familial hypercholesterolemia earlier in life by actively searching for affected children: the DECOPIN project. Atherosclerosis 278, 210-216. doi: 10.1016/j.atherosclerosis.2018.09.039

Julius, U. (2017). History of lipidology and lipoprotein apheresis. Atheroscler. Suppl. 30, 1-8. doi: 10.1016/j.atherosclerosissup.2017.05.034

Khan, S. P., Ghani, R., and Yaqub, Z. (2014). Single step PCR for the identification of Low Density Lipoprotein Receptor (LDL-R) gene mutations. Pak. J. Med. Sci. 30, 830-833. doi: 10.12669/pjms.304.4711

Klancar, G., Groselj, U., Kovac, J., Bratanic, N., Bratina, N., Trebusak Podkrajsek, K., et al. (2015). Universal screening for familial hypercholesterolemia in children. JACC 66, 1250-1257.

Knowles, J. W., Rader, D. J., and Khoury, M. J. (2017). Cascade screening for familial hypercholesterolemia and the use of genetic testing. JAMA 318, 381382. doi: 10.1001/jama.2017.8543

Kolansky, D. M., Cuchel, M., Clark, B. J., Paridon, S., McCrindle, B. W., Wiegers, S. E., et al. (2008). Longitudinal evaluation and assessment of cardiovascular disease in patients with homozygous familial hypercholesterolemia. Am. J. Cardiol. 102, 1438-1443. doi: 10.1016/j.amjcard.2008.07.035

Masana, L., Ibarretxe, D., Rodríguez-Borjabad, C., Plana, N., Valdivielso, P., PedroBotet, J., et al. (2019). Toward a new clinical classification of patients with familial hypercholesterolemia: one perspective from Spain. Atherosclerosis 287, 89-92. doi: 10.1016/j.atherosclerosis.2019.06.905

McKiernan, P. J. (2017). Recent advances in liver transplantation for metabolic disease. J. Inherit. Metab. Dis. 40, 491-495. doi: 10.1007/s10545-017-0020-z

Moorjani, S., Roy, M., Torres, A., Bétard, C., Gagné, C., Lambert, M., et al. (1993). Mutations of low-density-lipoprotein-receptor gene, variation in plasma cholesterol, and expression of coronary heart disease in homozygous familial hypercholesterolaemia. Lancet 341, 1303-1306. doi: 10.1016/0140-6736(93) 90815-x

Raal, F. J., Sjouke, B., Hovingh, K., and Isaac, B. J. (2016). Phenotype diversity among patients with homozygous familial hypercholesterolemia: a cohort study. Atherosclerosis 248, 238-244. doi: 10.1016/j.atherosclerosis.2016. 03.009

Rajendran, R., Srinivasa, K. H., Rangan, K., Hegde, M., and Ahmed, N. (2013). Supravalvular aortic stenosis in a patient with homozygous familial hypercholesterolaemia. Eur. Heart J. Cardiovasc. Imaging 14:1023. doi: 10. 1093/ehjci/jet072

Representatives of the Global Familial Hypercholesterolemia Community, Wilemon, K. A., Patel, J., Aguilar-Salinas, C., Ahmed, C. D., Alkhnifsawi, M., et al. (2020). Reducing the clinical and public health burden of familial hypercholesterolemia: a global call to action. JAMA Cardiol. 5, 217-229. 
Sanna, C., Stephenne, X., Revencu, N., Smets, F., Sassolas, A., Di Filippo, M., et al. (2016). Homozygous familial hypercholesterolemia in childhood: genotypephenotype description, established therapies and perspectives. Atherosclerosis 247, 97-104. doi: 10.1016/j.atherosclerosis.2016.02.009

Santos, R. D., Gidding, S. S., Hegele, R. A., Cuchel, M. A., Barter, P. J., Watts, G. F., et al. (2016). Defining severe familial hypercholesterolaemia and the implications for clinical management: a consensus statement from the international atherosclerosis society severe familial hypercholesterolemia panel. Lancet Diab. Endocrinol. 4, 850-861. doi: 10.1016/S2213-8587(16)30041-9

Sjouke, B., Hovingh, G. K., Kastelein, J. J., and Stefanutti, C. (2015). Homozygous autosomal dominant hypercholesterolaemia: prevalence, diagnosis, and current and future treatment perspectives. Curr. Opin. Lipidol. 26, 200-209. doi: 10. 1097/mol.0000000000000179

Sjouke, B., Kusters, D. M., Kindt, I., Besseling, J., Defesche, J. C., Sijbrands, E. J., et al. (2014). Homozygous autosomal dominant hypercholesterolaemia in The Netherlands: prevalence, genotype-phenotype relationship, and clinical outcome. Eur. Heart J. 36, 560-565. doi: 10.1093/eurheartj/ehu058

Sturm, A. C., Knowles, J. W., Gidding, S. S., Ahmad, Z. S., Ahmed, C. D., Ballantyne, C. M., et al. (2018). Clinical genetic testing for familial hypercholesterolemia JACC scientific expert panel. JACC 72, $662-680$.

Thompson, G., Seed, M., Naoumova, R. P., Neuwirth, C., Walji, S., Aitman, T. J., et al. (2015). Improved cardiovascular outcomes following temporal advances in lipid-lowering therapy in a genetically-characterised cohort of familial hypercholesterolaemia homozygotes. Atherosclerosis $243,328-333$. doi: 10.1016/j.atherosclerosis.2015.09.029
Umans-Eckenhausen, M. A., Defesche, J. C., Sijbrands, E. J., Scheerder, R. L., and Kastelein, J. J. (2001). Review of first 5 years of screening for familial hypercholesterolaemia in the Netherlands. Lancet 357, 165-168. doi: 10.1016/ s0140-6736(00)03587-x

Vallejo-Vaz, A. J., Kondapally Seshasai, S. R., Cole, D., Hovingh, G. K., Kastelein, J. J., Mata, P., et al. (2015). Familial hypercholesterolaemia: a global call to arms. Atherosclerosis 243, 257-259.

Watts, G. F., Gidding, S., Wierzbicki, A. S., Toth, P. P., Alonso, R., Virgil Brown, W., et al. (2014). Integrated guidance on the care of familial hypercholesterolaemia from the international FH foundation: executive summary. J. Atheroscler. Thromb. 21, 368-374.

Widhalm, K., Benke, I. M., Fritz, M., Geiger, H., Helk, O., Fritsch, M., et al. (2017). Homozygous familial hypercholesterolemia: summarized case reports. Atherosclerosis 257, 86-89. doi: 10.1016/j.atherosclerosis.2017.01.002

Conflict of Interest: The authors declare that the research was conducted in the absence of any commercial or financial relationships that could be construed as a potential conflict of interest.

Copyright (C) 2020 Marusic, Sustar, Sadiq, Kotori, Mlinaric, Kovac, Shafi, Khan, Cevc, Trebusak Podkrajsek, Battelino and Groselj. This is an open-access article distributed under the terms of the Creative Commons Attribution License (CC BY). The use, distribution or reproduction in other forums is permitted, provided the original author(s) and the copyright owner(s) are credited and that the original publication in this journal is cited, in accordance with accepted academic practice. No use, distribution or reproduction is permitted which does not comply with these terms. 